\title{
Article \\ Thermal Analysis on Active Heat Dissipation Design with Embedded Flow Channels for Flexible Electronic Devices
}

\author{
Yanan Yu ${ }^{1}$, Yafei Yin ${ }^{1}$, Yuhang $\mathrm{Li}^{1, * \mathbb{D}}, \mathrm{Min} \mathrm{Li}^{1}$ and Jizhou Song ${ }^{2,3, * \mathbb{D}}$ \\ 1 Institute of Solid Mechanics, Beihang University (BUAA), Beijing 100191, China; kiana_yuu@163.com (Y.Y.); \\ 13231040@buaa.edu.cn (Y.Y.); limin@buaa.edu.cn (M.L.) \\ 2 Department of Engineering Mechanics, Soft Matter Research Center, and Key Laboratory of Soft Machines \\ and Smart Devices of Zhejiang Province, Zhejiang University, Hangzhou 310027, China \\ 3 State Key Laboratory of Fluid Power and Mechatronic Systems, Zhejiang University, Hangzhou 310027, China \\ * Correspondence: liyuhang@buaa.edu.cn (Y.L.); jzsong@zju.edu.cn (J.S.)
}

Citation: Yu, Y.; Yin, Y.; Li, Y.; Li, M.; Song, J. Thermal Analysis on Active Heat Dissipation Design with Embedded Flow Channels for Flexible Electronic Devices. Micromachines 2021, 12, 1165. https://doi.org/10.3390/ mi12101165

Academic Editor: Xian Zhang

Received: 27 August 2021

Accepted: 24 September 2021

Published: 28 September 2021

Publisher's Note: MDPI stays neutral with regard to jurisdictional claims in published maps and institutional affiliations.

Copyright: (c) 2021 by the authors. Licensee MDPI, Basel, Switzerland. This article is an open access article distributed under the terms and conditions of the Creative Commons Attribution (CC BY) license (https:/ / creativecommons.org/licenses/by/ $4.0 /)$.

\begin{abstract}
Heat generation is a major issue in all electronics, as heat reduces product life, reliability, and performance, especially in flexible electronics with low thermal-conductivity polymeric substrates. In this sense, the active heat dissipation design with flow channels holds great promise. Here, a theoretical model, validated by finite element analysis and experiments, based on the method of the separation of variables, is developed to study the thermal behavior of the active heat dissipation design with an embedded flow channel. The influences of temperature and flow velocity of the fluid on heat dissipation performance were systematically investigated. The influence of channel spacing on heat dissipation performance was also studied by finite element analysis. The study shows that performance can be improved by decreasing the fluid temperature or increasing the flow velocity and channel density. These results can help guide the design of active heat dissipation with embedded flow channels to reduce adverse effects due to excessive heating, thus enhancing the performance and longevity of electronic products.
\end{abstract}

Keywords: thermal analysis; flow channel; active heat dissipation; flexible electronics

\section{Introduction}

In recent years, electronic products have emphasized intelligence and miniaturization, which require higher performance at the integration level. In particular, flexible electronic devices represent a rapidly developing branch, which has enabled many new applications such as curvilinear electronics and bio-integrated electronics [1-6] due to their unique advantages of stretchability and flexibility [7-10]. Furthermore, hybrid flexible systems have been investigated, such as electrophysiology [11], multimodal [12], large-area pressure [13] and other functions [14]; such functions may lead to overheating in the system. Heat generation is a major issue when these electronic devices are in service. According to the Arrhenius relation, the thermal failure rate of flexible electronic devices has an exponential relationship with temperature [15], in which the failure probability doubles for every $10{ }^{\circ} \mathrm{C}$ increase in temperature. Additionally, the use of polymer materials with poor thermal conductivity as the substrate creates more challenges regarding heat dissipation in flexible electronic devices.

In order to solve this special challenge, many thermal designs have been reported to improve heat dissipation in flexible electronic devices. Our group focused on passive thermal designs to control and tune the thermal flow in order to achieve adequate heat dissipation. Li et al. [16] reported on an orthotropic substrate design to control the heat flow paths. Shi et al. [17] proposed a phase change material enabled functional soft composite to serve as the thermal protection substrate for wearable electronics. Other groups have developed various new materials to enhance thermal conductivity. Jeong et al. [18] and Bartlett et al. [19] embedded liquid metal inclusions into a polymer to achieve both 
flexibility and high thermal conductivity. Sun et al. [20] designed a flexible graphene aerogel-based composite phase change film for personal thermal management applications. Although the above designs were all passive, they hold promise for the thermal management of flexible electronic devices. Compared to passive thermal designs, active designs, which have been extensively studied for silicon electronics, could be more efficient in heat dissipation [21-23], and are attracting more and more attention. At present, a substrate with embedded flow channels is the most common active heat dissipation design, where fluid flowing in the channel takes away heat. The earliest microchannel for water on a silicon plate, designed by Tuckeman and Pease in the 1980s, was able to achieve $800 \mathrm{~W}$ heat dissipation on a $1 \mathrm{~cm}^{2}$ chip [24]. Perret et al. [25] performed a numerical analysis of heat transfer in rectangular, rhombic and hexagonal flow channels and found that the former had the lowest thermal resistance. Yong et al. [26] added fins to the traditional rectangular channel and found that a smaller fin angle and smaller fin pitch could better improve heat dissipation performance. Husain and Kim [27] studied the influence of the width-depth ratio of the channel on the heat transfer of the system.

Due to the very poor thermal conductivity of polymer substrates, passive heat dissipation methods cannot provide adequate efficiency. Introducing active fluid flow in channels embedded in soft polymer substrates may significantly improve the efficiency of heat dissipation. However, few research efforts have sought to quantitatively investigate the effects of fluid flowing in the channels embedded in a soft polymer substrate. Because of the complexity and difficulty of solving the active heat dissipation problem of fluid-solid coupling, all the studies mentioned above were primarily numerical analyses, lacking theoretical thermal analyses of the structure with embedded flow channels.

This paper aims to develop a theoretical model to investigate the thermal behavior of an active heat dissipation design with embedded flow channels. Finite element analysis and experiments are also carried out to validate the analytical model. The paper is structured as follows. Section 2 describes the theoretical model. Section 3 presents the results and a discussion. Section 4 presents the conclusion.

\section{Theoretical Model}

The active heat dissipation design with flow channels can be applied to the substrate for flexible electronic devices. Figure 1a schematically shows a typical soft substrate, which is made of polydimethylsiloxane (PDMS), with an embedded flow channel for active heat dissipation. Since the diameter of the flow channel is usually much smaller than the characteristic length of the substrate (e.g., thickness), axisymmetric treatment of the problem is reasonable. The hollow channel is located at the center of the substrate. The fluid can flow in the channel along the direction indicated by the arrow changing from blue to red. Among the many liquid materials flowing in the channel, water is the most common, due to its nontoxicity, large specific heat capacity and availability. Figure $1 \mathrm{~b}$ is a schematic diagram of the theoretical model. The origin of coordinates $(r, z)$ is set at the center of the middle surface of the flow channel. $R_{\mathrm{c}}$ and $R_{\mathrm{S}}$ denote the channel radius and substrate radius, respectively. $H$ is the length of the flow channel. Path 1, Path 2 and Path 3 represent the inlet surface, the fluid-solid contact surface and the symmetric surface, respectively. 
a)

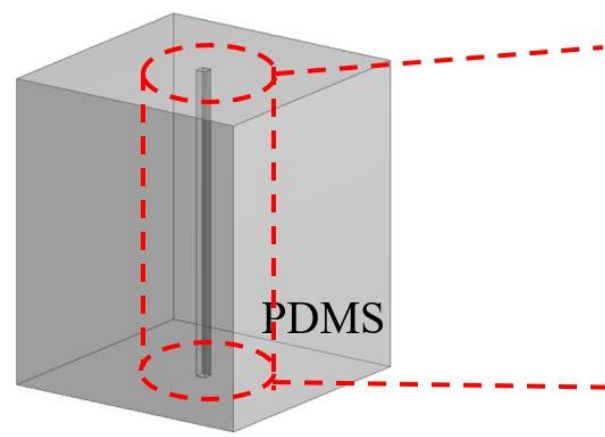

b)

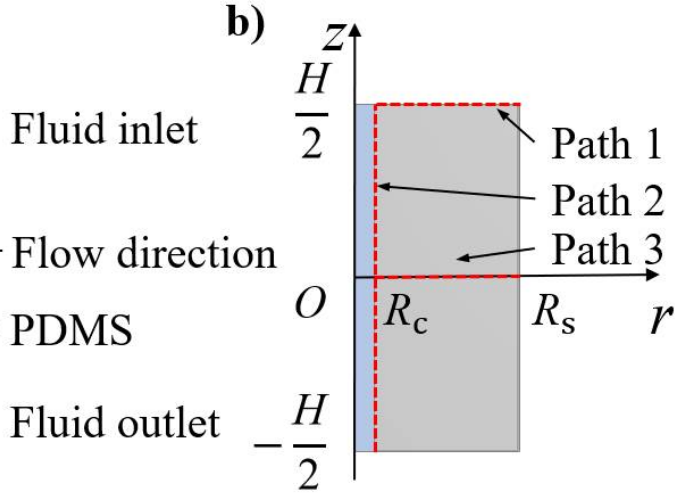

Figure 1. Schematic diagrams of (a) a typical active heat dissipation design with an embedded flow channel and the axisymmetric treatment of the problem, and (b) the theoretical model.

The steady temperature field $T(r, z)$ of the PDMS substrate satisfies the following axisymmetric heat transfer equation

$$
\frac{\partial^{2} T}{\partial r^{2}}+\frac{1}{r} \frac{\partial T}{\partial r}+\frac{\partial^{2} T}{\partial z^{2}}=0,0<z<\frac{H}{2}, R_{\mathrm{c}}<r<R_{\mathrm{s}}
$$

The fluid-solid coupling at the interface $\left(r=R_{\mathrm{c}}\right)$ can be simplified as a forced convention, while the coefficient $h_{\mathrm{f}}$ of heat convention can be obtained by the Sieder-Tate formula as [28],

$$
h_{\mathrm{f}}=\frac{k_{\mathrm{f}}}{2 R_{\mathrm{c}}} 1.86\left(\operatorname{Re} \cdot \operatorname{Pr} \cdot \frac{2 R_{\mathrm{c}}}{H}\right)^{1 / 3}
$$

where $\operatorname{Re}=\frac{\rho_{\mathrm{f}} v \cdot 2 R_{\mathrm{c}}}{\mu_{\mathrm{f}}}$ and $\operatorname{Pr}=\frac{c_{\mathrm{f}} \mu_{\mathrm{f}}}{k_{\mathrm{f}}}$ are the Reynolds number representing the convective strength and the Prandtl number representing relationship between temperature and flow boundary layers of the fluid, respectively, and $k_{\mathrm{f}}, \rho_{\mathrm{f}}, \mu_{\mathrm{f}}, c_{\mathrm{f}}$ are the thermal conductivity, density, viscosity and specific heat capacity of the fluid, respectively. Since the radius of the flow channel is smaller than that of substrate, the fluid has a negligible influence on the outer boundary of the PDMS. Therefore, the boundary conditions of the PDMS along the radial direction can be expressed as

$$
\left\{\begin{array}{l}
-\left.k \frac{\partial T}{\partial r}\right|_{r=R_{\mathrm{c}}}=-h_{\mathrm{f}}\left(\left.T\right|_{r=R_{\mathrm{c}}}-T_{\mathrm{f}}\right) \\
\left.T\right|_{r=R_{\mathrm{s}}}=T_{0}
\end{array}\right.
$$

where $k$ and $T_{0}$ are the thermal conductivity and initial temperature of the substrate, respectively, and $T_{\mathrm{f}}$ is the temperature of fluid.

The fluid temperature in the channel remains almost the same [29], such that the plane at $z=0$ can be considered a symmetric plane. Moreover, a natural convection occurs at the upper surface of the PDMS. Thus, the boundary conditions along the axial direction can be expressed as:

$$
\left\{\begin{array}{l}
-\left.k \frac{\partial T}{\partial z}\right|_{z=0}=0 \\
-\left.k \frac{\partial T}{\partial z}\right|_{z=\frac{H}{2}}=h_{\mathrm{a}}\left(\left.T\right|_{z=\frac{H}{2}}-T_{\mathrm{a}}\right)
\end{array}\right.
$$

where $h_{\mathrm{a}}$ is the natural convective coefficient and $T_{\mathrm{a}}$ is the ambient temperature.

We define the temperature rise from ambient temperature as $\theta=T-T_{a}$. The heat transfer Equation (1) and boundary conditions in Equations (3) and (4) then become

$$
\frac{\partial^{2} \theta}{\partial r^{2}}+\frac{1}{r} \frac{\partial \theta}{\partial r}+\frac{\partial^{2} \theta}{\partial z^{2}}=0,0<\mathrm{z}<\frac{H}{2}, R_{\mathrm{c}}<r<R_{\mathrm{S}}
$$




$$
\begin{aligned}
& \left\{\begin{array}{l}
-\left.k \frac{\partial \theta}{\partial r}\right|_{r=R_{\mathrm{c}}}=-h_{\mathrm{f}}\left(\left.\theta\right|_{r=R_{\mathrm{c}}}+T_{\mathrm{a}}-T_{\mathrm{f}}\right) \\
\left.\theta\right|_{r=R_{\mathrm{s}}}=T_{0}-T_{\mathrm{a}}
\end{array}\right. \\
& \left\{\begin{array}{l}
-k \frac{\partial \theta}{\partial z} \\
-\left.k \frac{\partial \theta}{\partial z}\right|_{z=\frac{H}{2}}=\left.h_{\mathrm{a}} \theta\right|_{z=\frac{H}{2}}
\end{array}\right.
\end{aligned}
$$

The method of separation of variables was adopted to solve the above heat transfer problem. The temperature rise $\theta$ takes the following form:

$$
\theta(r, z)=X(r) Y(z)
$$

where $Y(z)$ and $X(r)$ satisfy

$$
\frac{\partial^{2} Y}{\partial z^{2}}+\gamma^{2} Y=0
$$

and

$$
\frac{\partial^{2} X}{\partial r^{2}}+\frac{1}{r} \frac{\partial X}{\partial r}-\gamma^{2} X=0
$$

with $\gamma$ as the eigenvalue. Equations (7), (9) and (10) yield the solution of $\theta$ as:

$$
\theta(r, z)=\sum_{n=1}^{\infty}\left[A_{\mathrm{n}} I_{0}\left(\gamma_{\mathrm{n}} r\right)+B_{\mathrm{n}} K_{0}\left(\gamma_{\mathrm{n}} r\right)\right] \cos \left(\gamma_{\mathrm{n}} z\right)
$$

where $I_{0}$ and $K_{0}$ is the 0 -th order modified Bessel function of the first and second kinds, respectively, $\gamma_{\mathrm{n}}$ satisfies $k \gamma \sin (\gamma H / 2)-h_{\mathrm{a}} \cos (\gamma H / 2)=0$, and coefficients $A_{\mathrm{n}}$ and $B_{\text {n }}$ satisfy

$\left[\begin{array}{cc}I_{1}\left(\gamma_{\mathrm{n}} R_{\mathrm{c}}\right) \gamma_{\mathrm{n}} k-I_{0}\left(\gamma_{\mathrm{n}} R_{\mathrm{c}}\right) h_{1} & -\left[K_{1}\left(\gamma_{\mathrm{n}} R_{\mathrm{c}}\right) \gamma_{\mathrm{n}} k+K_{0}\left(\gamma_{\mathrm{n}} R_{\mathrm{c}}\right) h_{\mathrm{f}}\right] \\ I_{0}\left(\gamma_{\mathrm{n}} R_{\mathrm{s}}\right) & K_{0}\left(\gamma_{\mathrm{n}} R\right)\end{array}\right]\left\{\begin{array}{c}A_{\mathrm{n}} \\ B_{\mathrm{n}}\end{array}\right\}=\left\{\begin{array}{c}h_{\mathrm{f}}\left(T_{\mathrm{a}}-T_{\mathrm{f}}\right) \\ T_{0}-T_{\mathrm{a}}\end{array}\right\} \frac{G_{\mathrm{n}}}{N_{\mathrm{n}}}$

Here, $N_{\mathrm{n}}=\int_{z=0}^{H / 2} Y^{2}\left(\gamma_{\mathrm{n}}, z\right) \mathrm{d} z, G_{\mathrm{n}}=\int_{z=0}^{H / 2} Y\left(\gamma_{\mathrm{n}}, z\right) \mathrm{d} z, I_{1}$ and $K_{1}$ are the first-order modified Bessel function of the first and second kinds, respectively. Coefficients $A_{\mathrm{n}}$ and $B_{\mathrm{n}}$ can be given by:

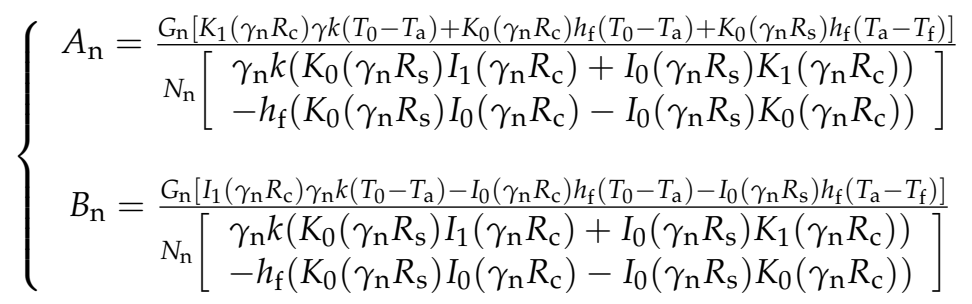

The temperature field $T(r, z)$ can then be obtained as:

$$
T(r, z)=T_{\mathrm{a}}+\theta(r, z)=T_{\mathrm{a}}+\sum_{n=1}^{\infty} X_{\mathrm{n}}(r) Y_{\mathrm{n}}(z)
$$

\section{Results and Discussion}

\subsection{Model Verification}

We carried out experiments and finite element analysis (FEA) to validate our theoretical model. Figure 2a shows the experimental setup. A flow channel with a radius $R_{\mathrm{c}}$ of $1 \mathrm{~mm}$ and a length $H$ of $60 \mathrm{~mm}$ was embedded in a PDMS substrate with the radius $R_{\mathrm{s}}$ of $25 \mathrm{~mm}$. The inlet was connected to an injector containing ice in order to keep the fluid cold. The cold fluid was pumped to the flow channel by an injection pump at a flow rate of $90 \mathrm{~mL} / \mathrm{min}$, and then flowed out through the PDMS into a liquid storage tank. The tem- 
perature of the PDMS was measured using an infrared thermal imager. Figure $2 b$ shows the infrared thermal imager measurements at the inlet of channel. The fluid temperature at the inlet was $4.3{ }^{\circ} \mathrm{C}$ and the environmental temperature $T_{\mathrm{a}}$ was $24.6^{\circ} \mathrm{C}$. Figure $2 \mathrm{c}$ shows the temperature distribution on the upper inlet surface of the structure.

a)

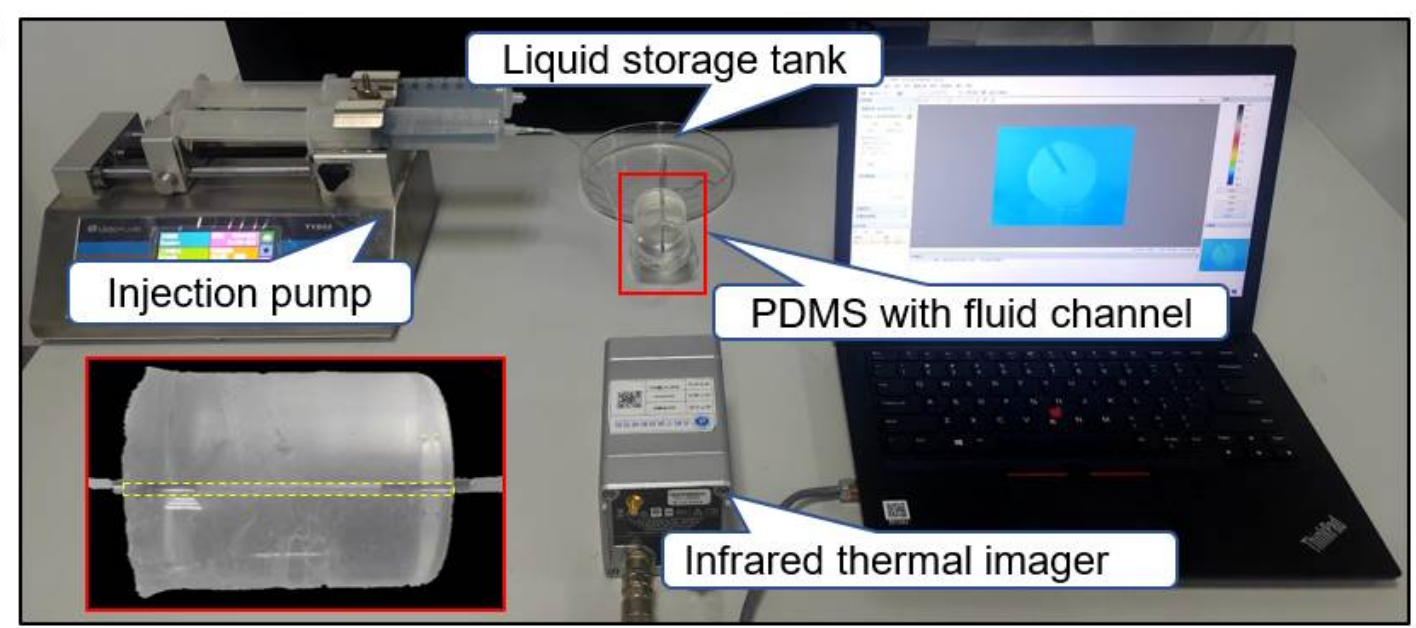

b)

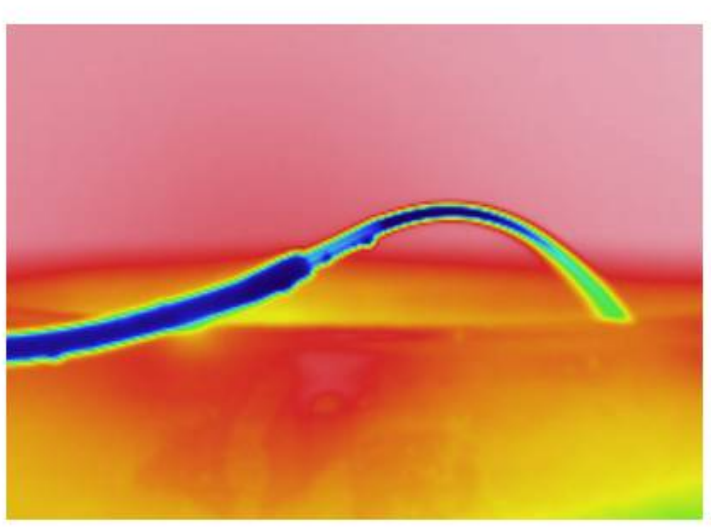

c)

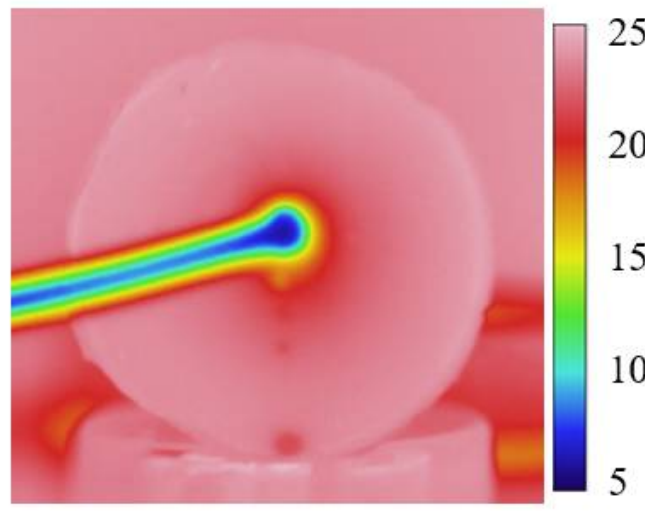

Figure 2. (a) Image of the experimental setup. (b) Thermal image at the inlet of channel. (c) Thermal image of the inlet surface.

The fluid-solid coupling FEA was performed using the commercial software, FLUENT. The thermal conductivity $k$ of PDMS was $0.17 \mathrm{~W} /(\mathrm{K} \cdot \mathrm{m})$. The parameters of fluid (i.e., water) were set to $0.6 \mathrm{~W} /(\mathrm{K} \cdot \mathrm{m})$ for the thermal conductivity $k_{\mathrm{f}}, 998.2 \mathrm{Kg} / \mathrm{m}^{3}$ for the mass density $\rho_{\mathrm{f}}, 0.001003 \mathrm{~Pa} \cdot \mathrm{s}$ for the viscosity $\mu_{\mathrm{f}}$, and $4182 \mathrm{~J} /(\mathrm{kg} \cdot \mathrm{K})$ for the specific heat capacity $\mathrm{c}_{\mathrm{f}}$. The initial temperature $T_{0}$ was equal to the ambient temperature $T_{\mathrm{a}}$; both were set to $24.6{ }^{\circ} \mathrm{C}$. The coefficient of thermal convection $h_{\mathrm{a}}$ was defined as $20 \mathrm{~W} /\left(\mathrm{K} \cdot \mathrm{m}^{2}\right)$ [30].

In order to measure the heat dissipation capacity of the flow channel, we defined a relative temperature drop affected by flow channel as:

$$
Q=\frac{T_{0}-T}{T_{0}-T_{\mathrm{f}}} \times 100 \%
$$

Figure 3 shows the temperature along Path 1, where the bar representing the experimental error was obtained from three experiments. The theoretical predictions agreed well with the FEA and experiments, which validates the accuracy of our theoretical model. As expected, the temperature increased as the distance to the channel increased, which yielded a decreasing heat dissipation capacity. For example, at $r=2 \mathrm{~mm}$, the temperature of PDMS was $12.3^{\circ} \mathrm{C}$, and $Q=61.3 \%$. When $r$ increased to $6 \mathrm{~mm}$, the temperature increased to $19.7{ }^{\circ} \mathrm{C}$ and $Q$ decreased to $Q=25.6 \%$. These results indicate that the flow channel significantly reduced the temperature of the PDMS. If a relative temperature drop 
of $25 \%$ was set as a criterion for heat dissipation, the influence range of flow channel on temperature was six times its own radius $R_{\mathrm{c}}$.

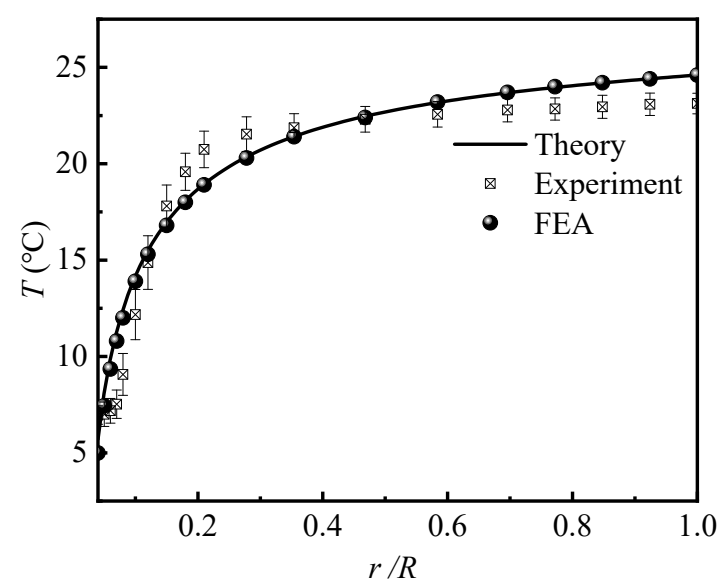

Figure 3. Temperature distribution along Path 1.

\subsection{Influences of Fluid Temperature and Flow Velocity}

In order to investigate the influence of fluid temperature on the thermal behavior of the active heat dissipation design, theoretical predictions and FEA were carried out with $T_{\mathrm{f}}$ of $5 / 10 / 15^{\circ} \mathrm{C}$. The initial and ambient temperature were $25^{\circ} \mathrm{C}$ and the fluid velocity was $100 \mathrm{~mm} / \mathrm{s}$. Figure 4a shows the temperature along Path 2. Again, there was good agreement between the theoretical prediction and FEA and the maximum temperature difference of $0.56^{\circ} \mathrm{C}$. As expected from FEA, the temperature of the PDMS decreased slightly along the flowing direction, since the heat was taken away by the flowing fluid. This slight temperature change validated the theoretical treatment of the influence of flowing fluid as a forced convection with a constant convective coefficient, although the local convective coefficient decreased along the flowing direction. Figure $4 \mathrm{~b}$ compares the temperature along Path 3 according to the theoretical prediction and FEA with various fluid temperatures of $5 / 10 / 15^{\circ} \mathrm{C}$. It can be observed that the theoretical prediction agreed well with FEA. As expected, lower fluid temperature yielded better heat dissipation performance. At the location of $r=10 \mathrm{~mm}$, the temperatures of PDMS were $19.6^{\circ} \mathrm{C}$, $21{ }^{\circ} \mathrm{C}$ and $22.3{ }^{\circ} \mathrm{C}$ for fluid temperatures of $5{ }^{\circ} \mathrm{C}, 10{ }^{\circ} \mathrm{C}$ and $15^{\circ} \mathrm{C}$ respectively. It was interesting to find that although the temperatures at the same location were different for different fluid temperatures, the temperature drop percentages $Q$ were all $27 \%$, which indicated that the influence range of flow channel on heat dissipation was not affected by the fluid temperature $T_{\mathrm{f}}$.

a)

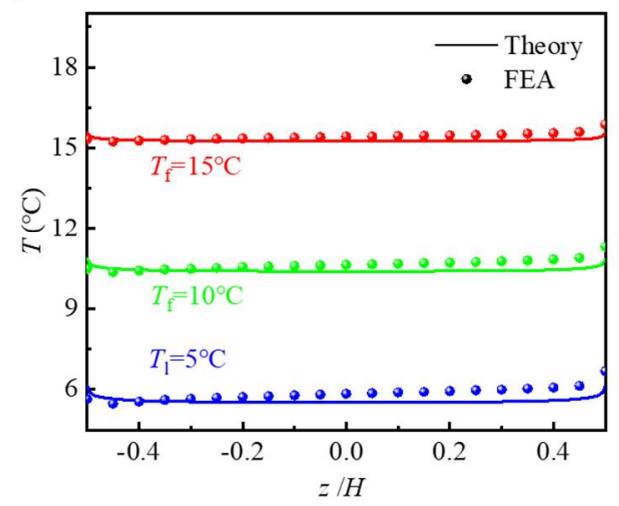

b)

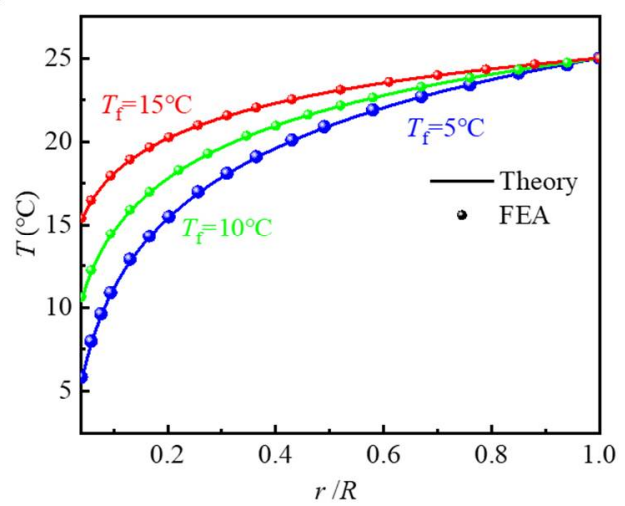

Figure 4. Temperature distributions along (a) Path 2 and (b) Path 3. 
Figure 5a shows the convective coefficient on the flow channel wall as a function of flow velocity from the Sieder-Tate formula. As shown, the convective coefficient increased with increasing fluid velocity. When the flow velocity increased from $20 \mathrm{~mm} / \mathrm{s}$ to $800 \mathrm{~mm} / \mathrm{s}$, the coefficient $h_{\mathrm{f}}$ increased from $1172 \mathrm{~W} /\left(\mathrm{K} \cdot \mathrm{m}^{2}\right)$ to $4010 \mathrm{~W} /\left(\mathrm{K} \cdot \mathrm{m}^{2}\right)$. In addition, the convective coefficient $h_{\mathrm{f}}$ increased rapidly when flow velocity $v$ was small, while the changing of coefficient $h_{\mathrm{f}}$ became slow when Re exceeded 640 . These results indicated that the flow velocity may affect the heat dissipation performance.

a)

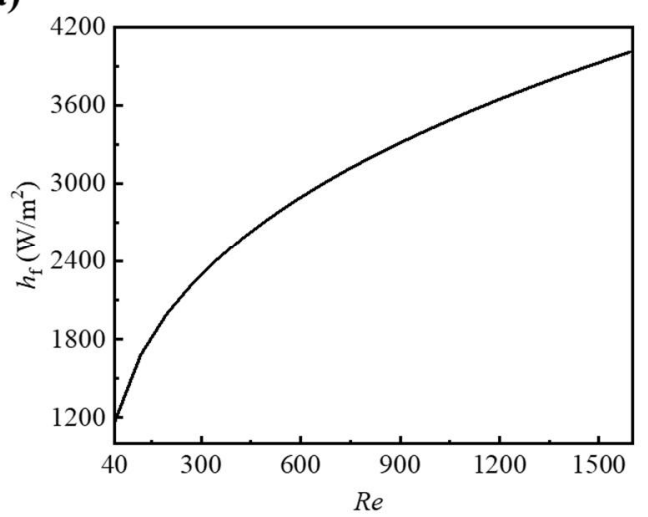

b)

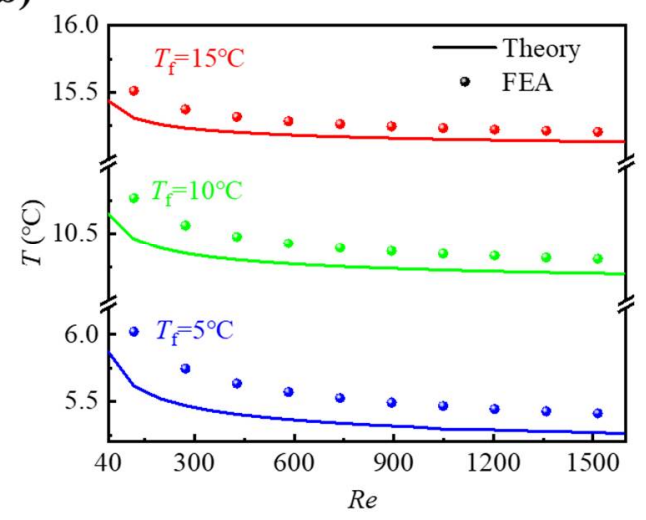

Figure 5. (a) Convective coefficient of the fluid-solid interface as a function of flow velocity. (b) The temperature at $\left(R_{\mathrm{c}}, 0\right)$ as a function of flow velocity.

To demonstrate the influence of flow velocity on the thermal behavior of the active heat dissipation design, we show the temperature at the feature point, $\left(R_{\mathrm{c}}, 0\right)$ as a function of flow velocity $v$ in Figure $5 b$, where the fluid temperature $T_{\mathrm{f}}$ was $5 / 10 / 15{ }^{\circ} \mathrm{C}$. It is shown that the FEA results were all higher than the theoretical predictions, since the actual higher local temperatures of the fluid at the fluid-solid interface were accounted for in FEA corresponding to a lower value of $T_{1}$ at the inlet in the theoretical model. When $T_{\mathrm{f}}$ was $5^{\circ} \mathrm{C}$, there was a more distinct difference between the FEA and theoretical prediction. The temperature differences were $0.4{ }^{\circ} \mathrm{C}$ for the $\operatorname{Re}$ of 120 and $0.14{ }^{\circ} \mathrm{C}$ for 780 . This temperature difference decreased with $R e$ because the added heat in the fluid, when flowing from the inlet to the feature point $\left(R_{\mathrm{c}}, 0\right)$, increased as the flow velocity $v$ slowed, resulting in a higher fluid temperature relative to the $T_{\mathrm{f}}$. Considering that the temperature differences between FEA and theoretical predictions were all lower than $0.4{ }^{\circ} \mathrm{C}$, it can be still considered that the theoretical predictions and FEA were in good agreement.

\subsection{Thermal Analysis of Active Heat Dissipation Design with Multiple Flow Channels}

The previous results and discussion were for the active heat dissipation design with a single flow channel. In order to further enhance the heat dissipation performance, multiple channels are usually adopted in practical applications. Figure 6a shows a cross-section of the active heat dissipation design with multiple flow channels, with $l$ representing the spacing of neighboring channels. As an analysis of the modelling of multiple channels was not possible, only FEA was carried out here to investigate the thermal behavior. Due to the symmetric conditions, a single unit cell was developed with a flow channel (radius: $1 \mathrm{~mm}$ ) located in the middle of a square PDMS (in-plane dimension: $l \times l$ ). The length of the flow channel was $60 \mathrm{~mm}$. The bottom and upper sides were set as natural convection boundaries with a coefficient of $20 \mathrm{~W} /\left(\mathrm{K} \cdot \mathrm{m}^{2}\right)$, and the remaining sides were set as the adiabatic boundaries. The initial and ambient temperatures were both set at $25^{\circ} \mathrm{C}$. The fluid temperature was $5^{\circ} \mathrm{C}$. 
a)

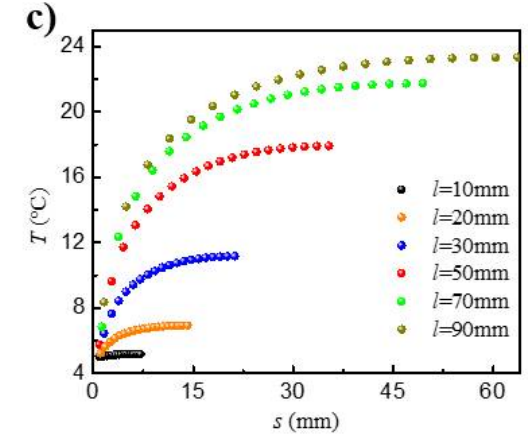

b)

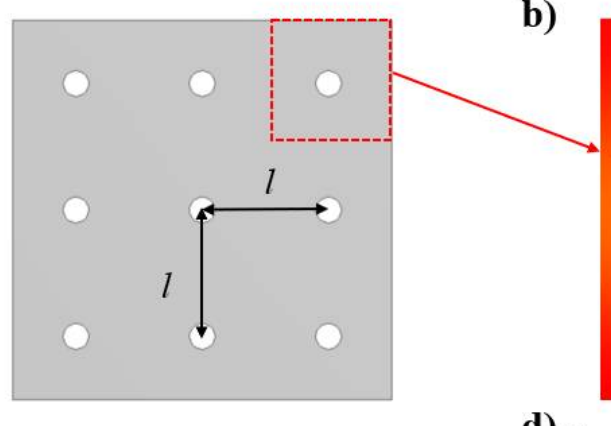

d)
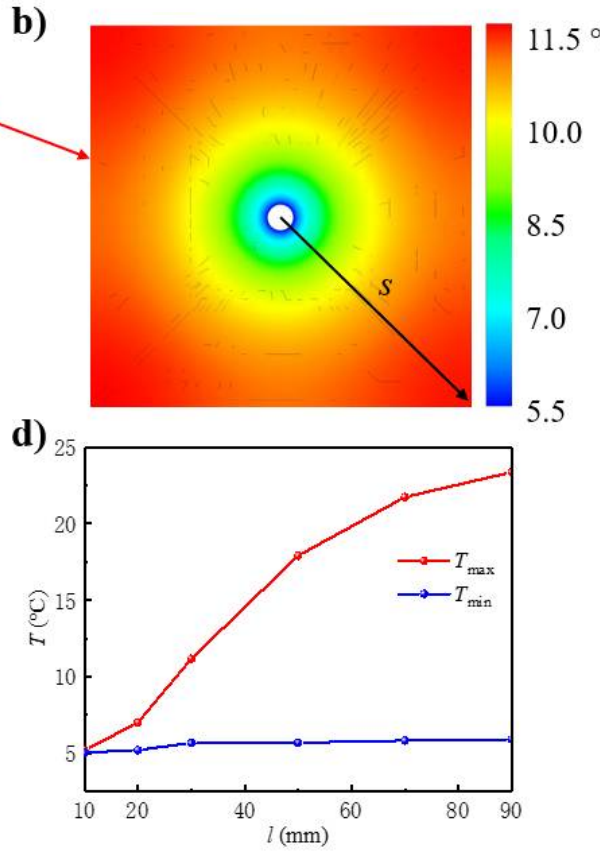

Figure 6. (a) Cross-sectional schematic of the active heat dissipation design with multiple flow channels in the soft substrate. (b) The temperature contour on the cross-section of the unit cell from FEA. (c) Temperature distribution along the diagonal with various channel spacings. (d) Maximum (red) and minimum (blue) temperatures as functions of the channel spacing.

Figure $6 \mathrm{~b}$ shows the temperature distribution on the cross-section of the unit cell with a spacing $l$ of $30 \mathrm{~mm}$. $s$ is defined as the distance between the point on the diagonal and the center. The maximum temperature, which occurred at the four corners of the unit cell, was $11.2{ }^{\circ} \mathrm{C}$, while the minimum temperature, which occurred at the fluid-solid interface, i.e., where the related temperature drop $Q$ ranged from $69 \%$ to $96.5 \%$, was $5.7^{\circ} \mathrm{C}$. Figure $6 \mathrm{c}$ shows the temperature distribution along the diagonal with spacing $l$ in the range of 10 to $90 \mathrm{~mm}$. The maximum temperature increased with the increase of spacing, since a larger spacing yields a lower heat dissipation capacity, resulting in a higher temperature. When the channel spacing $l$ was $90 \mathrm{~mm}$, the PDMS temperature was $19.6{ }^{\circ} \mathrm{C}$, and $Q$ was only $27 \%$ at the position of 15 times the channel radius away from the center compared to the same temperature at the position six times the channel radius for the case of a single flow channel. Thus, the heat dissipation influence of multiple channels is much better than that of a single channel. Figure $6 \mathrm{~d}$ shows the maximum and minimum temperatures on the cross-section with respect to the channel spacing $l$. The channel spacing had a significant influence on the maximum temperature but a negligible influence on the minimum temperature. When the spacing increased from $10 \mathrm{~mm}$ to $90 \mathrm{~mm}$, the maximum temperature increased by $350 \%$, i.e., from $5.2{ }^{\circ} \mathrm{C}$ to $23.4{ }^{\circ} \mathrm{C}$, and $Q$ decreased from $99 \%$ to $8 \%$, while the minimum temperature only increased by $18 \%$, i.e., from $5.0^{\circ} \mathrm{C}$ to $5.9^{\circ} \mathrm{C}$, and $Q$ was almost constant. Moreover, when the spacing was larger than the influence range of a single channel, its effect became negligible. However, under the same flow rate, the smaller spacing meant that the number of channels increased, which made it necessary to improve the pump power to overcome the pressure drop. Therefore, in practical applications, the contradiction between the number of channels and cooling performance needs to be adjusted so that cooling capacity and energy saving are maximized.

\section{Conclusions}

In summary, a theoretical model based on the method of separation of variables was developed to investigate the thermal behavior of an active heat dissipation design with an embedded flow channel. The fluid-solid coupling at the interface was simplified, i.e., to forced convention. Finite element analysis and experiments were also carried 
out to validate the analytical model. It was found that the temperature and velocity of the fluid had distinct heat dissipation effects on the system. Specifically, decreasing the former and increasing the latter significantly improved the heat dissipation performance. Furthermore, the active heat dissipation design with multiple channels was also studied by finite element analysis. It was found that denser flow channels have a much better heat dissipation performance.

Author Contributions: Conceptualization, Y.L. and J.S.; methodology, Y.Y. (Yanan Yu); software, Y.Y. (Yanan Yu); validation, Y.Y. (Yanan Yu) and Y.Y. (Yafei Yin); formal analysis, Y.Y. (Yafei Yin); investigation, Y.Y. (Yanan Yu) and Y.Y. (Yafei Yin); resources, Y.L.; data curation, Y.Y. (Yanan Yu); writing-original draft preparation, Y.Y. (Yanan Yu) and Y.Y. (Yafei Yin); writing-review and editing, M.L., Y.L. and J.S.; visualization, Y.Y. (Yanan Yu) and M.L.; supervision, J.S.; project administration, Y.L.; funding acquisition, Y.L. and J.S. All authors have read and agreed to the published version of the manuscript.

Funding: The authors acknowledge the supports from the National Natural Science Foundation of China (Grant No. 11772030, 11872331, and U20A6001), the Aeronautical Science Foundation of the PR China (2018ZC51030) and Opening fund of State Key Laboratory of Structural Analysis for Industrial Equipment, Dalian University of Technology (GZ19117).

Conflicts of Interest: The authors declare no conflict of interest.

\section{References}

1. Ausra, J.; Wu, M.Z.; Zhang, X.; Vázquez-Guardado, A.; Skelton, P.; Peralta, R.; Avila, R.; Murickan, T.; Haney, C.R.; Huang, Y.G.; et al. Wireless, battery-free, subdermally implantable platforms for transcranial and long-range optogenetics in freely moving animals. Proc. Natl. Acad. Sci. USA 2021, 118, e2025775118. [CrossRef]

2. Ghaffari, R.; Rogers, J.A.; Ray, T.R. Recent progress, challenges, and opportunities for wearable biochemical sensors for sweat analysis. Sens. Actuators B Chem. 2021, 332, 129447. [CrossRef]

3. Beker, L.; Matsuhisa, N.; You, I.; Ruth, S.R.A.; Niu, S.M.; Foudeh, A.; Tok, J.B.H.; Chen, X.D.; Bao, Z.A. A bioinspired stretchable membrane-based compliance sensor. Proc. Natl. Acad. Sci. USA 2020, 117, 11314-11320. [CrossRef] [PubMed]

4. Wang, C.J.; Cai, M.; Hao, Z.M.; Nie, S.; Liu, C.Y.; Du, H.G.; Wang, J.; Chen, W.Q.; Song, J.Z. Stretchable, multifunctional epidermal sensor patch for surface electromyography and strain measurements. Adv. Intell. Syst. 2021, 2100031. [CrossRef]

5. Yu, K.; Rich, S.; Lee, S.; Fukuda, K.; Yokota, T.; Someya, T. Organic photovoltaics: Toward self-powered wearable electronics. Proc. IEEE 2019, 107, 2137-2154. [CrossRef]

6. Jinno, H.; Yokota, T.; Koizumi, M.; Yukita, W.; Saito, M.; Osaka, I.; Fukuda, K.; Someya, T. Self-powered ultraflexible photonic skin for continuous bio-signal detection via air-operation-stable polymer light-emitting diodes. Nat. Commun. 2021, $12,2234$. [CrossRef] [PubMed]

7. Ma, Q.; Zhang, Y.H. Mechanics of fractal-inspired horseshoe microstructures for applications in stretchable electronics. J. Appl. Mech. 2016, 83, 111008. [CrossRef]

8. Zhang, F.; Li, S.P.; Shen, Z.M.; Cheng, X.; Xue, Z.G.; Zhang, H.; Song, H.L.; Bai, K.; Yan, D.J.; Wang, H.L.; et al. Rapidly deployable and morphable 3D mesostructures with applications in multimodal biomedical devices. Proc. Natl. Acad. Sci. USA 2021, 118, e2026414118. [CrossRef] [PubMed]

9. Zhang, S.; Wang, C.J.; Linghu, C.H.; Wang, S.H.; Song, J.Z. Mechanics strategies for implantation of flexible neural probes. J. Appl. Mech. 2021, 88, 010801. [CrossRef]

10. Nie, S.; Cai, M.; Wang, C.J.; Song, J.Z. Fatigue life prediction of serpentine interconnects on soft elastomers for stretchable electronics. J. Appl. Mech. 2020, 87, 011011. [CrossRef]

11. Wang, Y.H.; Yin, L.; Bai, Y.Z.; Liu, S.Y.; Wang, L.; Zhou, Y.; Hou, C.; Yang, Z.Y.; Wu, H.; Ma, J.J.; et al. Electrically compensated, tattoo-like electrodes for epidermal electrophysiology at scale. Sci. Adv. 2020, 6, eabd0996. [CrossRef]

12. Zhu, C.; Guo, D.L.; Ye, D.; Jiang, S.; Huang, Y.A. Flexible PZT-integrated, bilateral sensors via transfer-free laser lift-off for multimodal measurements. ACS Appl. Mater. Interfaces 2020, 12, 37354-37362. [CrossRef] [PubMed]

13. O'Neill, S.J.K.; Gong, H.X.; Matsuhisa, N.; Chen, S.C.; Moon, H.; Wu, H.C.; Chen, X.F.; Chen, X.D.; Bao, Z.N. A carbon flower based flexible pressure sensor made from large-area coating. Adv. Mater. Interfaces 2020, 7, 2000875. [CrossRef]

14. Rogers, J.A.; Chen, X.D.; Feng, X. Flexible hybrid electronics. Adv. Mater. 2020, 32, 1905590. [CrossRef] [PubMed]

15. Manca, J.V.; Wondrak, W.; Croes, K.; De Ceuninck, W.; D'Haeger, V.; De Schepper, L.; Tielemans, L. The Arrhenius relation for electronics in extreme temperature conditions. In Proceedings of the 3rd European Conference on High Temperature Electronics, Berlin, Germany, 4-7 July 1999; IEEE: Piscataway, NJ, USA, 1999.

16. Li, Y.H.; Chen, J.; Xing, Y.F.; Song, J.Z. Thermal management of micro-scale inorganic light-emitting diodes on an orthotropic substrate for biointegrated applications. Sci. Rep. 2017, 7, 6638. [CrossRef] [PubMed] 
17. Shi, Y.L.; Wang, C.J.; Yin, Y.F.; Li, Y.H.; Xing, Y.F.; Song, J.Z. Functional soft composites as thermal protecting substrates for wearable electronics. Adv. Funct. Mater. 2019, 29, 1905470. [CrossRef]

18. Jeong, S.H.; Chen, S.; Huo, J.X.; Gamstedt, E.K.; Liu, J.H.; Zhang, S.L.; Zhang, Z.B.; Hjort, K.; Wu, Z.G. Mechanically stretchable and electrically insulating thermal elastomer composite by liquid alloy droplet embedment. Sci. Rep. 2015, 5, 18257. [CrossRef]

19. Bartlett, M.D.; Kazem, N.; Powell-Palm, M.J.; Huang, X.N.; Sun, W.H.; Malen, J.A.; Majidi, C. High thermal conductivity in soft elastomers with elongated liquid metal inclusions. Proc. Natl. Acad. Sci. USA 2017, 114, 2143-2148. [CrossRef]

20. Sun, K.Y.; Dong, H.S.; Kou, Y.; Yang, H.N.; Liu, H.Q.; Li, Y.G.; Shi, Q. Flexible graphene aerogel-based phase change film for solar-thermal energy conversion and storage in personal thermal management applications. Chem. Eng. J. 2021, $419,129637$. [CrossRef]

21. Zhang, H.Y.; Pinjala, D.; Teo, P.S. Thermal management of high power dissipation electronic packages: From air cooling to liquid cooling. In Proceedings of the 5th Electronics Packaging Technology Conference, Singapore, 10-12 December 2003; IEEE: Piscataway, NJ, USA, 2003; pp. 620-625.

22. Lin, L.; Chen, Y.Y.; Zhang, X.X.; Wang, X.D. Optimization of geometry and flow rate distribution for double-layer microchannel heat sink. Int. J. Therm. Sci. 2014, 78, 158-168. [CrossRef]

23. Husain, A.; Kim, K.Y. Optimization of a microchannel heat sink with temperature dependent fluid properties. Appl. Therm. Eng. 2015, 28, 1101-1107. [CrossRef]

24. Tuckerman, D.; Pease, R. High-performance heat sinking for VLSI. IEEE Electron Device Lett. 1981, 2, 126-129. [CrossRef]

25. Perret, C.; Schaeffer, C.; Boussey, J. Microchannel integrated heat sinks in silicon technology. In Proceedings of the 33rd Industry Applications Society Annual Meeting, St. Louis, MO, USA, 12-15 October 1998; IEEE: Piscataway, NJ, USA, 1998 ; pp. $1051-1055$.

26. Lee, Y.J.; Singh, P.K.; Lee, P.S. Fluid flow and heat transfer investigations on enhanced microchannel heat sink using oblique fins with parametric study. Int. J. Heat Mass Transf. 2015, 81, 325-336. [CrossRef]

27. Husain, A.; Kim, K.Y. Shape Optimization of micro-channel heat sink for micro-electronic cooling. IEEE Trans. Compon. Packag. Technol. 2008, 31, 322-330. [CrossRef]

28. Sieder, E.N.; Tate, G.E. Heat transfer and pressure drop of liquids in tubes. Ind. Eng. Chem. 1936, 28, 1429-1435. [CrossRef]

29. Chen, H.T.; Chou, J.C. Investigation of natural-convection heat transfer coefficient on a vertical square fin of finned-tube heat exchangers. Int. J. Heat Mass Transf. 2006, 49, 3034-3044. [CrossRef]

30. Sefik, B. Laminar flow heat transfer in pipes including two-dimensional wall and fluid axial conduction. Int. J. Heat Mass Transf. 1995, 38, 1619-1625. 